\title{
HISTÓRIA DA EDUCAÇÃO MATEMÁTICA
}

\author{
HISTORY OF MATHEMATICS EDUCATION
}

Desde, pelo menos, os anos 1930, no Brasil, anunciam-se tensões entre a matemática, como campo disciplinar e o ensino de matemática. Em realidade, constitui anacronismo, a esse tempo, denominar "campo disciplinar matemático" o lugar ocupado por professores que ministram cursos de matemática no ensino secundário. Em sua quase totalidade, são eles engenheiros. É somente a partir de finais da década de 1930, tendo em vista o surgimento das faculdades de filosofia, que se passa a ter professores formados em matemática.

As tensões relativas ao ensino de matemática, cujo ícone foi Euclides Roxo - professor de matemática e diretor do Colégio Pedro II (ele mesmo com formação em engenharia) -, de fato representam embates que colocam, de um lado, os professores com inserção no campo educacional e, de outro, os engenheiros sem afinidade com as discussões educativas. A proximidade ao campo educacional de professores de matemática, como Euclides Roxo, também pode ser explicada por reflexos do movimento internacional do início do século XX, tendo à frente o eminente matemático Félix Klein. Àquela altura, fica posto o desafio a todos os países de estabelecerem continuidade dos ensinos secundário e superior em matemática. Isso faz emergir, de modo inédito, entre os matemáticos, o interesse pelo ensino elementar de sua disciplina.

De qualquer modo, reestabelecidas essas referências mais precisas, é importante destacar que, pelo menos a partir das primeiras décadas do século XX, no Brasil, há um debate de caráter público sobre a matemática e o ensino de matemática, debate esse que está mais voltado ao campo do exercício da docência em matemática, o campo profissional. No centro das atenções está a matemática que deve ser ensinada. As disputas concentram-se sobre programas de ensino, orientações para o trabalho pedagógico, livros didáticos de matemática etc. Quem tem autoridade para dar referências ao que se deve ensinar em matemática e como ensinar essa disciplina?

Mais adiante, caminhando-se para a segunda metade do século XX, a essa tensão relativa ao campo profissional ajunta-se aquela do campo científico, de pesquisa. Agudizam-se as disputas, tendo em vista a criação de cursos de pósgraduação. As tensões dizem respeito a publicações sobre o ensino de matemática. Mostra-se exíguo o espaço para a circulação de artigos escritos por professores com formação matemática, dedicados ao ensino, buscando refletir sobre questões de práticas profissionais docentes dessa disciplina. Os meios de publicação desses textos parecem estar tomados por autores do campo da educação. Há necessidade de, para julgar essa produção, serem instituídas autoridades que, ao mesmo tempo, tenham uma expertise em matemática e, além disso, proximidade com a educação. 
A julgar pela emergência internacional da educação matemática, esses dois tipos de tensões - a de caráter ligado aos profissionais da docência e a de caráter disciplinar científico - também estão presentes em diferentes países. Elas parecem ser molas mestras para a criação do novo campo da Educação Matemática.

Assim, em finais da década de 1980, surge um novo campo disciplinar e profissional: a Educação Matemática. A emergência desse novo campo tem, no Brasil, como marcos referenciais a realização do Encontro Nacional de Educação Matemática (I ENEM), em 1987, em São Paulo, e, no ano seguinte, no Paraná, a reunião entre professores que criaram a Sociedade Brasileira de Educação Matemática (SBEM).

Desde o tempo de sua constituição, a Educação Matemática mostra-se múltipla, apresentando diferentes tendências, tais como: etnomatemática; resolução de problemas; tecnologias no ensino de matemática; modelagem matemática; história da matemática; entre outras. Estudos mais específicos, ligados diretamente ao ensino de matemática sob a ótica dessas diferentes tendências, agora podem mostrar-se sem amarras a cânones mais amplos do campo educacional, assim como têm possibilidade de manter uma autonomia relativa do campo disciplinar matemático.

De outra parte, com a criação da Educação Matemática, novos desafios são postos para o tratamento do tema da formação de professores. As diferentes vertentes da educação matemática passam a dar contribuições à formação de professores no âmbito de suas especificidades. É possível dizer que a matemática que deve ser ensinada e aquela da formação de professores estão presentes como tema importante em cada uma dessas tendências agrupadas no interior do novo campo disciplinar em questão. Que matemática deve constituir o saber para formar professores e que matemática deve ser ensinada na escola básica?

A história da matemática, como vertente do novo campo, enseja a possibilidade de agregar à Educação Matemática o conhecimento histórico. Para além disso, abre caminho para a caracterização de uma nova vertente: a história da educação matemática (HEM).

Sabe-se que, do ponto de vista da criação de um novo campo disciplinar, surgem novas disciplinas, novos desmembramentos do campo inicial, ramificando o leque de possibilidades de construção de novas searas de pesquisa e mesmo profissionais:

O processo de disciplinarização não se completa com a generalização do sistema de disciplinas, mas prossegue incansavelmente sob múltiplas formas. As disciplinas se constituem frequentemente umas em relação às outras ou mesmo umas contra as outras, em um movimento de incessante reconfiguração [...] (HOFSTETTER; SCHNEUWLY, 2017, p. 25).

A HEM é exemplo dessa ramificação e dessa reconfiguração. A partir da inclusão das possibilidades didático-pedagógicas da história da matemática no ensino em referências curriculares desde a década de 1990, com os chamados Parâmetros Curriculares Nacionais (PCN) (BRASIL, 1998), tem-se uma valorização e um incremento de estudos sobre o papel da HEM.

De outra parte, se o uso didático da história da matemática passou a ter mais reconhecimento no âmbito escolar, profissional, isso não é acompanhado pela pesquisa em história da matemática. No seio mesmo dos congressos e reuniões relativos à história da matemática emergem de modo bastante 
significativo trabalhos sobre a HEM. Um estudo realizado por Mendes (2014) revela que mais da metade de todos os trabalhos escritos no âmbito da história da matemática, de 1990 a 2010, no Brasil, em realidade não tratam de história da matemática; referem-se a estudos de HEM. Além disso, ao que tudo indica, na década seguinte, essa tendência torna-se ainda mais acentuada, com crescimento exponencial de estudos sobre esse assunto. Essa representatividade crescente das pesquisas sobre HEM vem permitir a criação de congressos nacionais e internacionais sobre essa disciplina. Também a criação de revistas especializadas em HEM, com destaque para a HISTEMAT - Revista de História da Educação Matemática, órgão da própria Sociedade Brasileira de História da Matemática. Por fim, nesse movimento da HEM, tem-se a sistematização de trabalhos, estudos e resultados de pesquisas, de modo a formarem um conjunto de saberes para a formação de licenciandos, conduzindo à criação de uma disciplina intitulada "História da Educação Matemática". Todos esses elementos, entre outros, vão permitindo a caracterização de uma nova seara disciplinar: a história da educação matemática.

Este número temático justifica-se quer pela divulgação de estudos que vêm sendo realizados em âmbito nacional e internacional, quer por expressar a existência de uma diversidade de temas, tratando dos ensinos de matemática nos primeiros anos escolares, nos anos intermediários e finais da escola elementar e, ainda, no Ensino Superior. Além disso, o dossiê apresenta filiações teóricometodológicas diversas entre os vários artigos que o compõem.

Acreditamos que este dossiê poderá mostrar-se relevante por fomentar de modo incisivo o debate sobre o papel da HEM na formação dos futuros professores que ensinarão matemática.

Os textos que compõem este número voltado à história da educação matemática focam assuntos diversos, mas podem agrupar-se em três temáticas principais, a saber: história de conteúdos do ensino de matemática; história de professores de matemática e história dos processos de institucionalização de novos saberes matemáticos. No primeiro caso, têm destaque o desenho, a aritmética e o cálculo diferencial e integral. Em termos de história de professores de matemática, a relevância das pesquisas que distinguem tais personagens liga-se ao papel exercido por eles na sistematização da matemática para o ensino e para a formação de professores numa dada época e em dado local. Assim, ganham evidência as trajetórias de Aldebaro Klautau, Everardo Backheuser e Osvaldo Sangiorgi. Por fim, a temática dos processos de institucionalização de novos saberes matemáticos está presente nos estudos que envolvem a Espanha e os Estados Unidos.

As temáticas abordadas por este número temático, no âmbito da HEM, revelam, a partir da análise dos últimos eventos científicos da área, uma convergência de interesses dos pesquisadores, convergência essa que incide no debate sobre a construção histórica da matemática presente no ensino e na formação de professores. Tal saber é considerado nas pesquisas como diverso daquele do campo disciplinar matemático. Assim, há uma premissa levada em conta pelos estudos: historicamente, vem sendo elaborada uma matemática como objeto de ensino do professor e outra da formação de professores, essa última considerada ferramenta para o ensino.

Em meio às pesquisas sobre os processos e dinâmicas de elaboração dessas matemáticas distintas da matemática do campo disciplinar matemático, emergem personagens considerados experts. Ao seguir a trajetória profissional desses atores, cria-se a possibilidade de realizar análises das mudanças de finalidades e conteúdos de ensino e movimentos de institucionalização de novos saberes matemáticos a estar presentes na formação de professores e no ensino. Tais temáticas são tratadas neste dossiê. 


\section{REFERÊNCIAS}

BRASIL. Secretaria de Educação Fundamental. Parâmetros curriculares nacionais. Brasília, DF: MEC/SEF, 1998.

HOFSTETTER, R.; SCHNEUWLY, B. Disciplinarização e disciplinação: as ciências da educação e as didáticas das disciplinas sob análise. In: VALENTE, W.; HOFSTETTER, R. (Orgs.). Saberes em (trans)formação: tema central da formação de professores. São Paulo: Editora Livraria da Física, 2017.

MENDES, I. A. Cartografia da produção em História da Matemática no Brasil: um estudo centrado nas dissertações e teses defendidas entre 1990-2010. Relatório de Pesquisa. Bolsa Produtividade CNPq, 2014. Mimeografado. 